\title{
The fragile $x$-associated tremor and ataxia syndrome (FXTAS)
}

\author{
Leonardo Pires Capelli, Márcia Rúbia Rodrigues Gonçalves², \\ Claudia C. Leite ${ }^{3}$, Egberto R. Barbosa², Ricardo Nitrini², \\ Angela M. Vianna-Morgante ${ }^{1}$
}

\begin{abstract}
FXTAS (Fragile X-associated tremor and ataxia syndrome) is a late- onset neurodegenerative disorder affecting mainly men, over 50 years of age, who are carriers of the FMR1 gene premutation. The full mutation of this gene causes the fragile $X$ syndrome (FXS), the most common cause of inherited mental retardation. Individuals affected by FXTAS generally present intention tremor and gait ataxia that might be associated to specific radiological and/or neuropathological signs. Other features commonly observed are parkinsonism, cognitive decline, peripheral neuropathy and autonomic dysfunction. Nearly a decade after its clinical characterization, FXTAS is poorly recognized in Brazil. Here we present a review of the current knowledge on the clinical, genetic and diagnostic aspects of the disease. Key words: FXTAS, fragile X-associated tremor/ataxia syndrome, fragile $X$ syndrome, movement disorders, essential tremor, gait ataxia, CGG repeats, FMR1 gene.
\end{abstract}

\section{A síndrome de tremor e ataxia associada ao X frágil (FXTAS)}

\section{RESUMO}

A FXTAS (síndrome de tremor e ataxia associada ao X frágil) é uma doença neurodegenerativa de início tardio que afeta principalmente homens acima dos 50 anos de idade, portadores de pré-mutação do gene FMR1. A mutação completa desse gene é responsável pela síndrome do cromossomo X frágil (SXF), a causa mais comum de deficiência mental herdada. Indivíduos afetados pela FXTAS geralmente apresentam tremor de intenção e ataxia de marcha que podem estar associados a sinais radiológicos ou neuropatológicos específicos. Outras características comumente observadas são parkinsonismo, declínio cognitivo, neuropatia periférica e disfunções autonômicas. Quase uma década após sua caracterização clínica, a FXTAS é mal conhecida por médicos no Brasil. Esta revisão apresenta o conhecimento atual sobre os aspectos clínicos, genéticos e diagnósticos da síndrome. Palavras-chave: FXTAS, tremor e ataxia associados ao X frágil, síndrome do X frágil, distúrbios do movimento, tremor essencial, ataxia de marcha, repetições CGG, gene FMR1.

By the end of the 1990s, the occurrence of an unknown neurological disease affecting the elderly was brought to the attention of the Hagermans, at the University of Colorado, Denver, USA. For some years already, their main research interest had been the Fragile X Syndrome (FXS, MIM 300624), the most frequent form of inherited mental retardation, caused by the mutation of the FMR1 gene (Fragile X Mental Retardation 1 gene, MIM 309550), on the $\mathrm{X}$ chromosome. The recurrent reports on fallings and difficulties to perform daily activities in consequence of tremor experienced by maternal grandparents of the mentally retarded boys prompted them to investigate these complains in detail. In 2000, during the $7^{\text {th }}$ International Fragile $X$ Conference, Los Angeles, California, USA, attended by researchers, physicians and FXS relatives, a neurological evaluation of grandparents in FXS families was present- 
ed, and approximately one third of FXS relatives in the audience declared the presence of the neurological signs in elderly members of their families. This gave further support to the idea that a neurological syndrome was associated to the premutation of the FMR1 gene. This syndrome was characterized and named FXTAS (Fragile $X$ associated - tremor and ataxia syndrome; MIM 300623) ${ }^{1-3}$.

The FMR1 gene contains a 5' untranslated CGG repeat - $(C G G)_{n}$ - that is polymorphic in the general population, varying in length from 6 to about 55 triplets $\left[(\mathrm{CGG})_{6}\right.$ to $\left.(\mathrm{CGG})_{\sim 55}\right]$. Premutations are characterized by expanded $(\mathrm{CGG})_{\mathrm{n}}$ between 55 to 200 triplets; these alleles are functional, producing both messenger RNA (FMR1 mRNA) and protein (FMRP, fragile $X$ mental retardation protein). When the $(C G G)_{\mathrm{n}}$ is expanded to more than 200 triplets - a full mutation - the gene becomes non-functional, as the consequence of abnormal methylation of the adjacent $\mathrm{CpG}$ island and the repeat itself. The absence of the protein, the FMRP, is responsible for the fragile $\mathrm{X}$ syndrome, the most common cause of inherited mental retardation (review in Jacquemont and coleagues ${ }^{4}$ ).

The clinical picture of FXS (mental retardation, macroorchidism, facial abnormalities, joint laxity, hyperactivity and autistic features) is completely distinct from the FXTAS phenotype. In FXTAS, intention tremor and gait ataxia are the major clinical symptoms; parkinsonism, cognitive decline, peripheral neuropathy and autonomic dysfunctions might be associated. Radiological and neuropathological features also contribute to the establishment of the FXTAS diagnostic. The relatively recent nine-year description of the FXTAS contrasts with about three decades of clinical characterization of the FXS and the identification of FMR1 as the gene responsible for the disease 19 years ago $^{2}$. This late recognition of FXTAS might be the consequence of the occurrence of two completely distinct clinical entities associated with the same gene: a neurodevelopmental disease, the FXS, present since childhood without any significant progression during adulthood, and a late-onset neurodegenerative disorder manifested after the fifth decade of life, the FXTAS. In addition, it was believed that the functional premutation could not cause neurological problems, and the movement disorders observed in a number of elderly FXS relatives were ascribed to the aging process ${ }^{2,5,6}$.

FXTAS is not the only condition associated to the premutation of the FMR1 gene. Premutated women tend to present primary ovarian insufficiency (FXPOI, fragile Xassociated primary ovarian insufficiency), and about $20 \%$ of them have premature menopause (POF, cessation of menses before 40 years of age $)^{7,8}$.

\section{FXTAS - Case description}

Here we summarize the clinical and radiological fea- tures of one male patient affected by FXTAS who was identified in a Brazilian FXS/FXTAS/POF family reported by Capelli and coleagues ${ }^{9}$. This patient, a retired watchman, started with gait difficulties and frequent fallings due to the sensation of weakness in the lower limbs, at the age of 59 years. In the following years, intention tremor appeared in the upper limbs, impairing execution of daily tasks, as eating and writing. At 72 years of age, a cane was necessary to support locomotion. Neurological examination, at 74 years of age, revealed a definite low score in the Mini-Mental State Examination (18 points), despite his 8 years of schooling. The patient presented global cerebellar syndrome evidenced by tendon dance, dysarthria, gait ataxia, dyssynergy, dysdiadochokinesia and dysmetria, in addition to postural and kinetic tremor in the upper limbs, scoring 45/100 in ICARS. Mild parkinsonism was noticed by rest tremor in the right hand. A peripheral motor syndrome was detected, with reduction of strength in the lower limbs and absence of reflexes. Non-inhibited bladder was observed.

Magnetic resonance imaging (MRI) revealed in axial FLAIR images cortical and subcortical atrophy, symmetric lesions in the periventricular white matter and hypersignal in the middle cerebellar peduncle (Figure) .This patient passed away at the age of 77 years in an accident. Neuropathological analysis or autopsy of the brain was not performed. He was a carrier of a FMR1 premutation with $(\mathrm{CGG})_{109}$.

\section{FXTAS: Clinical, radiological and neuropathological aspects}

Following the initial description of FXTAS ${ }^{1}$, several studies on its symptoms and signs allowed establishing a clinical, radiological and pathological picture of the syndrome.

- Progressive intention tremor mainly observed during intentional movements aiming at performing daily tasks (eating, writing, and grabbing objects) or during maintenance of a position against gravity (postural tremor). Tremor causes moderate-to-severe incapacity, generally affecting the upper limbs, first the dominant hand, and then the other hand ${ }^{5,10}$.

- Gait Ataxia: FXTAS patients initially exhibit widebased gait, frequent fallings and incapacity of tandem gait. Progressively, locomotor supports (cane, walker) become necessary and, at the final stages of the disease, individuals are confined to wheelchairs or, eventually, bedridden ${ }^{10,11}$.

- Cognitive decline is generally evidenced by decrease of attention control, working memory, executive functioning, and learning in contrast to the relative preservation of speech, visual and spatial abilities. Mood and behavioral abnormalities such as depression, mood 


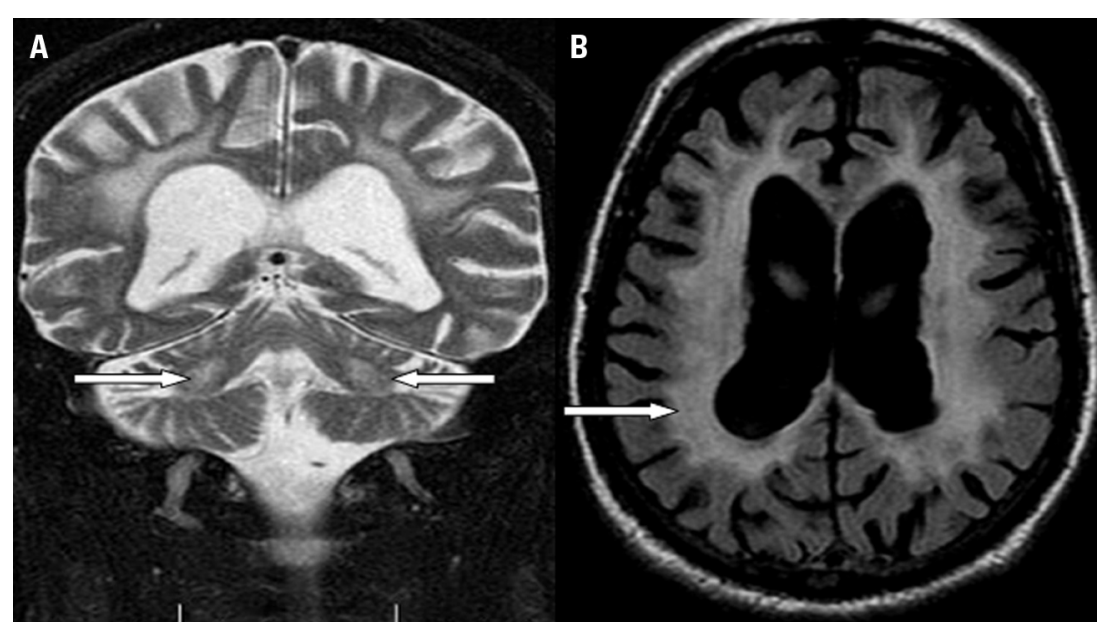

Figure. MRI features of a fragile X-associated tremor and ataxia syndorme patient: [A] increased T2 signal intensity (arrows) in white matter of the middle cerebellar peduncles; [B] increased signal intensity (arrow) on FLAIR images in periventricular and deep white matter of the hemispheres.

switches, disinhibition, irritability, inappropriate or reclusive behavior and anxiety are usually present. This pattern is consistent with the frontal-subcortical type of dementia. Generally the FXTAS leads to complete loss of autonomy due to dementia ${ }^{5,10-15}$.

- Parkinsonism is characterized by slowness of movements, rigidity, rest tremor and reduction of facial expression $^{10,16}$.

- Peripheral neuropathy affects the lower limbs and is characterized by decrease or loss of deep tendon reflexes, reduction of touch and vibration sensations, tingling, lower extremity pain, abnormalities in proprioceptive response, and muscular weakness in the proximal portion of the lower limbs ${ }^{2,10,17}$.

- Autonomic dysfunctions: bowel incontinency, bladder incontinency and impotence are frequently observed ${ }^{5}$.

The first symptom of the disease varies between intention tremor ${ }^{1,11,18,19}$ or gait ataxia ${ }^{2,5,10}$, generally beginning between 50 and 70 years of age (mean of 60 years). Not always these two symptoms appear concomitantly but, independently of the order of appearance, in up to two years they are generally present, as in the case reported above. Beginning of falls occurs around six years after the appearance of motor problems, and necessity of locomotion support is present between 5 to 15 years. Then, parkinsonism, peripheral neuropathy, cognitive decline and autonomic dysfunctions might appear. The diagnosis of FXTAS is performed approximately 10 years after the initial symptoms. Life expectancy is variable, between 5 to 25 years after diagnosis, with a mean of about 21 years. End-stages of FXTAS include laryngeal muscle weakness and death is commonly caused by dysphagia ${ }^{10,17,19,20}$.

In addition to the clinical features, radiological and neuropathological signs also contribute to establish the correct diagnosis of FXTAS. Magnetic resonance imaging (MRI) examination revealed an abnormal brain pattern, which allowed classifying the syndrome as a white matter disease, affecting the periventricular and the subcortical regions of the brain. The principal radiological sign is the hyperintensity of the middle cerebellar peduncle (MCP sign) seen in T2 and FLAIR acquisitions ${ }^{5,21}$, which is present in $60 \%$ of the FXTAS patients ${ }^{10}$. Generalized brain atrophy, with decrease in volume of cerebrum (mainly the parietal and frontal regions), mesencephalon, pons and cerebellum is observed, always disproportional for age ${ }^{21,22}$.

The abnormalities observed in MRI agreed with the neuroanatomical analyses of 11 brains of individuals who died with FXTAS, which exhibited degenerated regions and demyelination in white matter of cerebrum and cerebellum, mild to moderate cortical atrophy, increased size of the brain ventricles and spongiform intercellular edema in the middle cerebellar peduncle, corresponding to the MCP $\operatorname{sign}^{21,23}$.

Neuropathological analyses also contribute to FXTAS diagnosis. Postmortem examination revealed the presence of eosinophilic intranuclear inclusions in neurons and astrocytes throughout cortex, basal ganglia, thalamus, substantia nigra, dentate nucleus and brainstem, with the highest number in hippocampus. Inclusions were also observed in neurons of the cranial nerve XII, autonomic neurons of the spinal cord, ganglion cells of the adrenal medulla, dorsal root ganglia, paraspinal sympathetic ganglia, myenteric ganglia of the stomach and subepicardial autonomic ganglion of the heart. Inclusions were not present in oligodendrocytes, anterior horn neurons of the spinal cord, neurons of sural and sciatic nerves, and cells of skeletal muscles, urinary bladder and esophagus. Purkinje cells did not present inclusions either, but exhibited degenerative axonal swelling (torpedo formation) and Bergman gliosis $^{23-25}$. The presence of inclusions has not been evaluated in large cohorts of patients. It varies substantially between the few reported cases, and a possible relationship with FXTAS clinical variability has been suggested. However, further studies are necessary to clarify this issue ${ }^{25}$. 
The neuroanatomical and neuropathological findings could explain the clinical phenotypes of FXTAS patients: the brain atrophy in frontal and parietal regions associated with demyelination of the cerebral white matter and presence of inclusions in the cerebral neocortex, hippocampus and basal ganglia might explain the frontalsubcortical type of dementia with its cognitive and behavioral disturbances. The motor abnormalities could be the consequence of cerebellar degeneration associated with the presence of inclusions in substantia nigra, basal ganglia and brainstem. Inclusions in spinal cord probably explain the autonomic dysfunctions ${ }^{10,23,24}$. Recently, the presence of inclusions was reported in the pituitary gland and Leydig cells; moreover, hypothyroidism has been reported to be common in premutated women with FXTAS. These observations led to the proposal of hormonal dysfunction also being a feature of the clinical picture of FXTAS ${ }^{26,27}$.

FXTAS may affect premutated women, but the syndrome predominantly affects male carriers. This genderrelated difference might be the consequence of the random inactivation of one $\mathrm{X}$ chromosome in somatic cells of females. Premutation carriers, being mosaic of cells with the premutation or the normal allele as the active one, would have the symptoms alleviated or absent. A hormonal factor is also a possibility that cannot be excluded ${ }^{2}$.

\section{Possible molecular mechanism causing the FXTAS}

The two to 10 times higher levels of the FMR1 mRNA, associated with a mild decrease of FMRP, represent the molecular phenotype in premutated carriers compared to normal individuals. This molecular imbalance would be the consequence of a feedback mechanism probably related to a less effective processing of FMRP synthesis. The expanded $(\mathrm{CGG})_{\mathrm{n}}$ in the premutation mRNA would impair the protein synthesis, and the consequent reduced levels of FMRP would in turn lead to an elevated production of the mRNA. FXTAS has never been observed in carriers of the full mutation of the FMR1 gene. Since these individuals do not produce FMRP, the reduction of this protein per se cannot be the cause of FXTAS. A toxic-gain-of-function model of the FMR1 mRNA was then put forward, resembling that proposed for myotonic dystrophy ${ }^{2,28-30}$.

In this model, an over-interaction of trinucleotidebinding proteins and translational factors with the FMR1 mRNA would occur due to the excess of the FMR1 mRNA and/or to its expanded (CGG) $)_{n}$. As a consequence, the amount of these proteins and factors would be reduced in the cell pool, thus impairing several cellular process$\mathrm{es}^{2}$. These molecular abnormalities are associated with the appearance of eosinophilic nuclear inclusions. It was observed that the FMR1 mRNA was sequestered into these inclusions in neurons and astrocytes associated to proteins with critical neuronal functions, as myelin basic pro- tein, lamin $\mathrm{A} / \mathrm{C}, \alpha \beta$-crystallin, tropomyosin, hnRNPA2/ B1, Pur- $\alpha$ and CUGBP1 in addition to ubiquitin ${ }^{23,31-35}$. Microarray expression analysis of plasmids containing premutated alleles revealed alterations in genes involved in several functions as synapses, chaperones, ubiquitination, motor coordination and apoptosis ${ }^{36}$.

It is not precisely known if the process of inclusion formation is ubiquitously occurring in different brain regions. It is speculated that neurons presenting high amounts of FMR1 mRNA and associated proteins would request chaperones and components of the ubiquitin-proteasomal pathway, in an attempt to alleviate this molecular abnormality; in case of failure, the inclusions would be formed. Depending where this process occurred, the inclusions could have an initial protective effect, avoiding cell death, as in the hippocampus, with the highest concentration of inclusions. However, in different types of cells, the process of inclusion formation could be fast and highly toxic, triggering the apoptosis pathway, and causing neurodegeneration, as would be the case of the loss of Purkinje cells in the cerebellum ${ }^{32,37-39}$.

FXTAS represents a new class of inclusion diseases. Immunocytochemical studies showed that antibodies anti-tau and anti- $\alpha$-synuclein did not react against the FXTAS inclusions, evidencing a distinct clinical entity from diseases caused by the accumulation of tau protein (Pick disease) or synuclein (Parkinson disease). The FXTAS inclusions are also polyglutamine-negative, differing from those in CAG-expansion disorders. Finally, the localization of the inclusions (nucleus of neurons and astrocytes) distinguishes FXTAS from pathologies presenting similar clinical pictures, as multiple system atrophy (MSA), in which the inclusions are in the cytoplasm of oligodendrocytes ${ }^{2,24}$.

\section{Animal models for FXTAS}

The animal models constructed to study FXTAS confirmed the involvement of the expanded (CGG) $)_{\mathrm{n}}$ and/or the high levels of FMR1 mRNA in the process of inclusions formation.

The first animal used to study FXTAS was a mouse which had a constitutional $(\mathrm{CGG})_{8}$ replaced by an exogenous $(\mathrm{CGG})_{98}{ }^{40}$. This animal showed mild impairment of behavior, cognition and neuromotor aspects, associated to high levels of Fmr1-mRNA (two to four times). The inclusions started to appear at the 30th week of life and were restricted to neurons, differently from humans whose inclusions are also present in astrocytes. Immunocytochemical findings were similar to those in human neurons, and the size of the inclusions was directly related to the animal age. The absence of inclusions in astrocytes could explain the mild clinical picture in this FXTAS mouse model ${ }^{23,41}$. 
Table 1. Diagnostic criteria for FXTAS*.

\begin{tabular}{lll}
\hline Criteria & & \\
\hline Molecular (mandatory) & FMR1 premutation: $55<\mathrm{CGG}<200$ \\
Diagnostic & Definite & $\begin{array}{l}\text { One major clinical + One major radiological or } \\
\text { One major clinical + Intranuclear inclusions (postmortem) }\end{array}$ \\
& Probable & Two major clinical or \\
& One minor clinical + One major radiological \\
& Major & One major clinical + One minor radiological \\
Clinical & Minor & Parkinsonism; moderate to severe working memory deficit; executive function deficit \\
Radiological & MRI white matter lesions in the middle cerebellar peduncle (MCP sign) \\
& Minor & MRI lesions in the cerebral white matter; moderate to severe generalized brain atrophy \\
\hline
\end{tabular}

*Based on Jacquemont and coleagues ${ }^{5}$ and Berry-Kravis and coleagues ${ }^{57}$. FXTAS: fragile X-associated tremor and ataxia syndrome; MRI: magnetic resonance imaging; MCP: middle cerebellar.

Jin and colleagues ${ }^{42}$ used Drosophila as a model to study FXTAS. A human genomic fragment containing a (CGG) ${ }_{90}$ inserted through an expression vector into Drosophila cells was enough to cause neurodegeneration and disturb eye morphology, more pronounced with aging. Inclusions were observed in the nucleus as well as in the cytoplasm, with more than one inclusion per nucleus, contrasting with the single and nucleus-restricted inclusions in humans. These differences could reflect different protein-mRNA interactions in Drosophila.

Despite of the presence of inclusions in these animal models, the clinical symptoms and signs were considered extremely mild when compared to those in humans. Therefore, they cannot be considered as ideal models for the human FXTAS phenotype ${ }^{43}$.

\section{Diagnostic criteria for FXTAS}

The diagnostic criteria for FXTAS were proposed by Jacquemont and coleagues ${ }^{5}$, in a study of 26 affected individuals carrying the FMR1 premutation. Each category to discriminate FXTAS patients consists of a combination of clinical, radiological and pathological signs and symptoms (Table 1 ).

Based on these criteria, individuals are considered as being definitively affected by FXTAS if they present tremor or ataxia and the MCP sign or, otherwise, any major clinical or radiological sign associated to the observation of intranuclear inclusions in postmortem studies. Patients with a probable diagnosis of FXTAS present tremor and ataxia or the MCP sign associated with parkinsonism, memory or executive function deficit. Finally, possible FXTAS is attributed to those patients presenting ataxia or tremor, associated with white matter lesions or brain atrophy.

Although these signs and symptoms allow the establishment of FXTAS diagnosis with different degrees of certainty, the presence of the FMR1 premutation is man- datory for the final diagnosis. The detection of the premutation allows associating specific signs and symptoms to FXTAS, which, in a different circumstance, would be attributed to idiopathic neurodegenerative disease ${ }^{44}$. On contrary, the absence of the FMR1 premutation in the presence of major recognized clinical signs of FXTAS, including the presence of the MCP sign in MRI, excludes FXTAS diagnosis ${ }^{45}$.

The establishment of criteria to characterize the disease has improved the initial diagnosis as FXTAS, which is rarely done. The study of 56 FXTAS patients revealed that 98 different diagnoses were attributed to the patients before the definition of FXTAS ${ }^{20}$. Moreover, the clinical variability of the FXTAS, in terms of severity and disease progression, points to the interaction of genetic, neuronal and environmental factors, confusing the identification of at-risk individuals. For instance, significant motor impairment after surgical procedures involving general anesthesia has been reported in FXTAS patients ${ }^{5,46}$. This variability also brings difficulties to the categorizing of patients according to the proposed criteria ${ }^{10,19,39,47,48}$. Several studies reported atypical FXTAS patients. There are descriptions of asymptomatic premutation carriers whose image exam revealed the presence of white matter abnormalities or the MCP sign, thus indicating that MRI can evidence alterations before FXTAS clinical manifestations in elderly patients ${ }^{9,22,49,50}$. In some premutation carriers, the major clinical symptom was dementia without a clear evidence of motor impairment ${ }^{51,52}$. In a 65-year-old carrier of a premutation, a rapid cognitive decline was the major clinical symptom, and the postmortem analysis revealed the association of FXTAS and Alzheimer disease. The association of these two neurodegenerative diseases was proposed to explain the fast progression of the clinical picture ${ }^{46}$.

Despite the established diagnostic criteria being an invaluable tool for FXTAS diagnosis, the atypical cases call for a detailed study of neurological impairments in premu- 
tation carriers to evaluate how frequent these exceptions $\operatorname{are}^{19,20,53}$. A point that must be addressed is the possibility of detecting specific symptoms of FXTAS, as cognitive decline and radiological signs, in the initial stages of adulthood. This issue is important in two aspects: [1] to predict which carriers are in risk to develop FXTAS and [2] to understand how the high levels of FMR1-mRNA throughout lifespan could damage susceptible neural networks ${ }^{54,55}$.

\section{Premutation screening in patients with movement disorders}

In an attempt to better understand the clinical manifestations of the FXTAS, FMR1 premutation screenings have been performed in cohorts of patients presenting movement disorders. Clinical symptoms of FXTAS overlap with those of other neurological disorders as cerebellar ataxia, essential tremor, Parkinson disease and multiple system atrophy ${ }^{19,44,56}$.

FMR1 premutation screenings performed so far revealed a low frequency in movement disorders cohorts. However, in a meta-analysis of cross-sectional studies in men with ataxia, the prevalence of the premutation was $1.5 \%$, thirteen times more than expected considering the premutation frequency in the general population, and the frequency among patients with the cerebellar subtype of multiple system atrophy was $2.4 \%$; for other movement disorders, the screening has not been rewarding. In most of the premutation carriers detected in these studies, the clinical features suggested the FXTAS diagnosis (review in Berry -Kravis and coleagues ${ }^{57}$ ).

At the same time, these studies showed that the (CGG) size of the detected premutations were as expanded as the $(\mathrm{CGG})_{\mathrm{n}}$ in the FXTAS patients from FXS families (i.e., $\sim 70<\mathrm{CGG}<130$ ). It is possible that the premutation frequency in movement disorders cohorts is underestimated due to several factors: [1] inclusion of patients under 55 years of age, when FXTAS is not commonly observed; [2] small size of cohorts; [3] previously selection of patients through specific criteria that could have excluded FXTAS patients ${ }^{2,50,57-59}$. Up to now, which movement disorders are more suitable to be screened for the presence of the FMR1 premutation remain unknown ${ }^{60,61}$.

\section{FXTAS frequency}

The first study on the frequency of FXTAS among premutated men from FXS families ${ }^{56}$ revealed an age-dependent frequency: $17 \%$ among premutation carriers between 50 to 59 years of age; $38 \%$ among those between $60-69$ years; $47 \%$ in the group between $70-79$ years, and $75 \%$ among carriers aged over 80 years. The mean frequency of FXTAS estimated among male carriers over 50 years was $39 \%$.

Although some comparative analyses on FXTAS patients did not reveal an effect of the size of the (CGG) n on certain aspects of the disease, such as onset of signs, life expectancy and severity of neuropsychiatry symptoms ${ }^{10,11,12,19,62,63}$, several recent studies produced strong evidence of the effect of the size of the (CGG) on FXTAS manifestations, including cognitive and executive skills, motor dysfunctions, brain volumetric measures, initial age of symptoms and number of cells with intranuclear inclusions ${ }^{22,23,49,54,64-66}$. The influence of the repeat size on the penetrance of the disease is also supported by the finding that $86 \%$ of individuals with FXTAS have $(\mathrm{CGG})>70^{59}$. Taken together, available data suggest that FXTAS is most often associated with these large CGG repeats, although not exclusively ${ }^{4}$.

Based on the premutation frequency of 1:800 men from the general population ${ }^{67}$ and a penetrance for the disease of about $40 \%$, the expected FXTAS frequency in men over 50 years of age would be about 1:2,000 in the general population ${ }^{6}$. However, considering that alleles with $(\mathrm{CGG})_{<70}$ are less likely to be associated with FXTAS, and that only $22 \%$ of the premutations in the general population have $(C G G)_{>70}$, the expected frequency of the disease would lower to about 1:10,000 men. In a conservative calculation that considers premutations in the range $66<\mathrm{CGG}<70$, this frequency would reach about 1:5,000 men in the general population. In spite of these doubts on its real frequency as well as on the contribution to mortality and morbidity of elderly individuals, probably FXTAS is the most common cause of tremor and ataxia due to a single gene alteration ${ }^{4}$. It appears at least as prevalent as neurodegenerative diseases such as multiple system atrophy and amyotrophic lateral sclerosis ${ }^{57}$.

These estimations point to the underdiagnosing of FXTAS. In addition to the restricted knowledge about this syndrome, other factors certainly contribute to this situation. The clinical variability in FXTAS presentation might cause, for example the exclusion of those cases where the major symptom is dementia without motor impairment. Also, the clinical manifestations of FXTAS in elderly patients might be interpreted as consequence of the natural process of aging.

\section{Treatment}

There is no specific treatment to counteract the excess of the FMR1 mRNA in the cells of FXTAS patients. In theory, drugs aimed at suppressing or diminishing the interaction between the mRNA CGG repeat and proteins could hinder the sequestration of the latter, maintaining normal protein levels. RNA interference might be an interesting approach to be explored ${ }^{43}$.

Therapeutic attempts towards FXTAS patients are based on the treatment of disorders presenting with similar symptoms. The medicines are used, basically, to alleviate symptoms related to tremor, equilibrium coordina- 
Table 2. Therapeutic interventions in FXTAS patients.

\begin{tabular}{|c|c|}
\hline Symptoms & Therapies \\
\hline Tremor & Primidone, beta-blockers, benzodiazepines \\
\hline Ataxia & Amantadine and physical therapy \\
\hline Parkinsonism & $\begin{array}{l}\text { Carbidopa/levodopa, } \\
\text { pramipexole and eldepryl }\end{array}$ \\
\hline $\begin{array}{l}\text { Cognitive deficits } \\
\text { and dementia }\end{array}$ & $\begin{array}{l}\text { Donepezil, rivastigmine, } \\
\text { galantamine, memantine }\end{array}$ \\
\hline $\begin{array}{l}\text { Psychiatric } \\
\text { problems }\end{array}$ & $\begin{array}{l}\text { Sertraline, citalopram, escitalopram, } \\
\text { duloxetine, mirtazapine, } \\
\text { venlafaxine and aripiprazole }\end{array}$ \\
\hline $\begin{array}{l}\text { Autonomic } \\
\text { dysfunction }\end{array}$ & $\begin{array}{l}\text { Bladder incontinency: tricyclic } \\
\text { antidepressants, muscarinic receptor } \\
\text { antagonists, cytoscopy with injection } \\
\text { of Botox; swallowing difficulties: } \\
\text { pyridostgmine bromide }\end{array}$ \\
\hline Pain & $\begin{array}{l}\text { Antidepressants, antiepileptics, topical } \\
\text { analgesics, gabapentin and/or pregabalin }\end{array}$ \\
\hline
\end{tabular}

*Based on Hagerman and coleagues ${ }^{27}$ and Berry-Kravis and coleagues ${ }^{57}$. FXTAS: fragile $X$-associated tremor and ataxia syndrome.

tion, parkinsonism, sleep problems, anxiety, mood alterations, memory problems and pain ${ }^{10,53,68}$. Some interventions have produced reasonable results ${ }^{27,57}$ (Table 2).

\section{CONCLUSIONS}

The identification of the FXTAS, a late onset-neurological progressive disease without cure, affects genetic counseling in FXS families. Before 2001, genetic tests to identify carriers of the premutation in these families were performed in adults to assist them about the risks of mental retardation in their offspring. Nowadays, the detection of the FMR1 premutation, especially in men, has brought ethical issues, mainly the fact that it is predictive for an incurable disease, a situation akin of the screening of the HTT gene mutation for Huntington disease or the ApoE4 variant for Alzheimer disease ${ }^{69}$.

As far as we know, there are just a few reports concerning aspects of FXTAS in Brazi1 ${ }^{9,52,70,71}$. The disease has been first recognized by geneticists in the study of fragile $\mathrm{X}$ families. The knowledge of this relatively new syndrome by physicians and health professionals is fundamental for diagnosis and proper assistance to FXTAS patients to be achieved. The diagnosis of FXTAS in a family might also lead to the identification of premutation carrier women in risk for FXS in their offspring, or to a heretofore unknown diagnosis of FXS in a child.

The presence of the FMR1 premutation is recommended to be evaluated in men and women with late-onset intention tremor, cerebellar ataxia of unknown cause, dementia (mainly if associated to movement disorders) or MCP sign revealed by MRI. Major concern should be given to symptomatic individuals with [1] familial history of
FXS or mental retardation without a diagnosis; [2] female relatives presenting premature menopause; [3] relatives with ataxia, neurological or psychiatric problems $s^{13,20,44,57,72}$. The standards and clinical guidelines for FXTAS and FXS can be accessed at the American College of Medical Genetics web site (http://www.acmg.net/Pages/ACMG_ Activities/stds-2002/fx.htm $)^{73}$.

\section{REFERENCES}

1. Hagerman RJ, Leehey M, Heinrichs W, et al. Intention tremor, Parkinsonism, and generalized brain atrophy in male carriers of fragile X. Neurology 2001; 57:127-130.

2. Hagerman PJ, Hagerman RJ. The fragile-X premutation: a maturing perspective. Am J Hum Genet 2004;74:805-816.

3. Miller G. Biomedical research. Fragile X's unwelcome relative. Science 2006;312:518-521.

4. Jacquemont S, Hagerman RJ, Hagerman PJ, Leehey MA. Fragile-X syndrome and fragile $X$-associated tremor/ataxia syndrome: two faces of FMR1. Lancet Neurol 2007;6:45-55.

5. Jacquemont $\mathrm{S}$, Hagerman RJ, Leehey $\mathrm{M}$, et al. Fragile $X$ premutation tremor/ataxia syndrome: molecular, clinical, and neuroimaging correlates. Am J Hum Genet 2003;72:869-878.

6. Amiri K, Hagerman RJ, Hagerman PJ. Fragile X-associated tremor/ataxia syndrome: an aging face of the fragile $X$ gene. Arch Neurol 2008;65:19-25.

7. Allingham-Hawkins DJ, Babul-Hirji R, Chitayat D, et al. Fragile X premutation is a significant risk factor for premature ovarian failure: the International Collaborative POF in Fragile X study-preliminary data. Am J Med Genet 1999;83:322-325

8. Costa SS, Fonseca AM, Bagnoli VR, Vianna-Morgante AM. The FMR1 premutation as a cause of premature ovarian failure in Brazilian women. Genet Mol Biol 2006;29:423-428.

9. Capelli LP, Goncalves MR, Kok F, et al. Fragile X-associated tremor/ataxia syndrome: intrafamilial variability and the size of the FMR1 premutation CGG repeat. Mov Disord 2007;22:866-870.

10. Jacquemont S, Farzin F, Hall D, et al. Aging in individuals with the FMR1 mutation. Am J Ment Retard 2004;109:154-164.

11. Rogers C, Partington MW, Turner GM. Tremor, ataxia and dementia in older men may indicate a carrier of the fragile X syndrome. Clin Genet 2003; 64:54-56.

12. Bacalman S, Farzin F, Bourgeois JA, et al. Psychiatric phenotype of the fragile X-associated tremor/ataxia syndrome (FXTAS) in males: newly described fronto-subcortical dementia. J Clin Psychiatry 2006;67:87-94.

13. Bourgeois JA, Cogswell JB, Hessl D, et al. Cognitive, anxiety and mood disorders in the fragile X-associated tremor/ataxia syndrome. Gen Hosp Psychiatry 2007;29:349-356.

14. Grigsby J, Brega AG, Engle K, et al. Cognitive profile of fragile X premutation carriers with and without fragile $X$-associated tremor/ataxia syndrome. Neuropsychology 2008;22:48-60.

15. Seritan AL, Nguyen DV, Farias ST, et al. Dementia in fragile $X$-associated tremor/ataxia syndrome (FXTAS): comparison with Alzheimer's disease. Am J Med Genet B 2008;147:1138-1144.

16. Hall DA, Howard K, Hagerman R, Leehey MA. Parkinsonism in FMR1 premutation carriers may be indistinguishable from Parkinson disease. Parkinsonism Relat Disord 2009;15:156-159.

17. Hagerman RJ, Coffey SM, Maselli R, et al. Neuropathy as a presenting feature in fragile X-associated tremor/ataxia syndrome. Am J Med Genet A 2007; 143:2256-2260.

18. Grigsby J, Brega AG, Jacquemont S, et al. Impairment in the cognitive functioning of men with fragile X-associated tremor/ataxia syndrome (FXTAS). J Neurol Sci 2006;248:227-233.

19. Leehey MA, Berry-Kravis E, Min SJ, et al. Progression of tremor and ataxia in male carriers of the FMR1 premutation. Mov Disord 2007;22:203-206.

20. Hall DA, Berry-Kravis E, Jacquemont $S$, et al. Initial diagnoses given to persons with the fragile $X$ associated tremor/ataxia syndrome (FXTAS). Neurology 2005;65:299-301.

21. Brunberg JA, Jacquemont $S$, Hagerman RJ, et al. Fragile X premutation carriers: characteristic MR imaging findings of adult male patients with progressive cerebellar and cognitive dysfunction. Am J Neuroradiol 2002; 23:1757-1766. 
22. Loesch DZ, Litewka L, Brotchie P, Huggins RM, Tassone F, Cook M. Magnetic resonance imaging study in older fragile $X$ premutation male carriers. Ann Neurol 2005;58:326-330.

23. Greco CM, Berman RF, Martin RM, et al. Neuropathology of fragile X-associated tremor/ataxia syndrome (FXTAS). Brain 2006;129:243-255.

24. Greco CM, Hagerman RJ, Tassone F, et al. Neuronal intranuclear inclusions in a new cerebellar tremor/ataxia syndrome among fragile $X$ carriers. Brain 2002;125:1760-1771.

25. Gokden M, Al-Hinti JT, Harik SI. Peripheral nervous system pathology in fragile X tremor/ataxia syndrome (FXTAS). Neuropathology 2009;29: 280-284.

26. Coffey SM, Cook K, Tartaglia N, et al. Expanded clinical phenotype of women with the FMR1 premutation. Am J Med Genet A 2008;146:1009-1016.

27. Hagerman RJ, Hall DA, Coffey S, et al. Treatment of fragile X-associated tremor ataxia syndrome (FXTAS) and related neurological problems. Clin Interv Aging 2008;3:251-262.

28. Tassone F, Hagerman RJ, Taylor AK, Gane LW, Godfrey TE, Hagerman PJ. Elevated levels of FMR1 mRNA in carrier males: a new mechanism of involvement in the fragile-X syndrome. Am J Hum Genet 2000;66:6-15.

29. Mankodi A, Thornton CA. Myotonic syndromes. Curr Opin Neurol 2002;15: 545-552.

30. Primerano B, Tassone F, Hagerman RJ, Hagerman P, Amaldi F, Bagni C. Reduced FMR1 mRNA translation efficiency in fragile $X$ patients with premutations. RNA 2002;8:1482-1488.

31. Tassone F, Iwahashi C, Hagerman PJ. FMR1 RNA within the intranuclear inclusions of fragile X-associated tremor/ataxia syndrome (FXTAS). RNA Biol 2004;1:103-105.

32. Garcia-Arocena D, Iwahashi CK, Won N, et al. Induction of inclusion formation and disruption of lamin A/C structure by premutation CGG-repeat RNA in human cultured neural cells. Hum Mol Genet 2005;14:3661-3671.

33. Iwahashi $\mathrm{CK}$, Yasui $\mathrm{DH}, \mathrm{An} \mathrm{HJ}$, et al. Protein composition of the intranuclear inclusions of FXTAS. Brain 2006:129:256-271.

34. Jin P, Duan R, Qurashi A, et al. Pur alpha binds to rCGG repeats and modulates repeat-mediated neurodegenerationin a Drosophila model of fragile $X$ tremor/ataxia syndrome. Neuron 2007;55:556-564.

35. Sofola OA, Jin P, Qin Y, et al. RNA-binding proteins hnRNP A2/B1 and CUGBP1 suppress fragile X CGG premutation repeat-induced neurodegeneration in a Drosophila model of FXTAS. Neuron 2007;55:565-571.

36. Handa V, Goldwater D, Stiles D, et al. Long CGG-repeat tracts are toxic to human cells: implications for carriers of Fragile $X$ premutation alleles. FEBS Lett 2005:579:2702-2708.

37. Oostra BA, Willemsen R. A fragile balance: FMR1 expression levels. Hum Mol Genet 2003:12:249-257.

38. Willemsen R, Mientjes E, Oostra BA. FXTAS: a progressive neurologic syndrome associated with Fragile X premutation. Curr Neurol Neurosci Rep 2005;5:405-410.

39. Hagerman RJ. Lessons from fragile $X$ regarding neurobiology, autism, and neurodegeneration. J Dev Behav Pediatr 2006;27:63-74

40. Willemsen R, Hoogeveen-Westerveld M, Reis S, et al. The FMR1 CGG repeat mouse displays ubiquitin-positive intranuclear neuronal inclusions; implications for the cerebellar tremor/ataxia syndrome. Hum Mol Genet 2003;12:949-959.

41. Van Dam D, Errijgers V, Kooy RF, et al. Cognitive decline, neuromotor and behavioural disturbances in a mouse model for fragile-X-associated tremor/ataxia syndrome (FXTAS). Behav Brain Res 2005;162:233-239.

42. Jin P, Zarnescu DC, Zhang F, et al. RNA-mediated neurodegeneration caused by the fragile $X$ premutation rCGG repeats in Drosophila. Neuron 2003:39:739-747.

43. Shan G, Xu S, Jin P. FXTAS: a bad RNA and a hope for a cure. Expert Opin Biol Ther 2008;8:249-253.

44. Kamm C, Gasser T. The variable phenotype of FXTAS: a common cause of "idiopathic" disorders. Neurology 2005;65:190-191.

45. Storey E, Billimoria P. Increased T2 signal in the middle cerebellar peduncles on MRI is not specific for fragile X premutation syndrome. J Clin Neurosci 2005;12:42-43.

46. Mothersead PK, Conrad K, Hagerman RJ, Greco CM, Hessl D, Tassone F. GRAND ROUNDS: an atypical progressive dementia in a male carrier of the fragile $X$ premutation: an example of fragile $X$-associated tremor/ataxia syndrome. Appl Neuropsychol 2005;12:169-178.

47. Hagerman PJ, Hagerman RJ. Fragile X-associated tremor/ataxia syndrome (FXTAS). Ment Retard Dev Disabil Res Rev 2004;10:25-30.

48. Van Esch $H$. The Fragile $X$ premutation: new insights and clinical consequences. Eur J Med Genet 2006:49:1-8.
49. Cohen S, Masyn K, Adams J, et al. Molecular and imaging correlates of the fragile X-associated tremor/ataxia syndrome. Neurology 2006;67: 1426-1431.

50. Loesch DZ, Litewka L, Churchyard A, Gould E, Tassone F, Cook M. Tremor/ ataxia syndrome and fragile $X$ premutation: diagnostic caveats. J Clin Neurosci 2007;14:245-248.

51. Grigsby J, Leehey MA, Jacquemont S, et al. Cognitive impairment in a 65year-old male with the fragile $X$-associated tremor-ataxia syndrome ( $F X$ TAS). Cogn Behav Neurol 2006;19:165-171.

52. Gonçalves MR, Capelli LP, Nitrini R, et al. Atypical clinical course of FX TAS: rapidly progressive dementia as the major symptom. Neurology 2007;68:1864-1866

53. Hagerman PJ, Hagerman RJ. Fragile X-associated tremor/ataxia syndromean older face of the fragile X gene. Nat Clin Pract Neurol 2007;3:107-112.

54. Cornish KM, Li L, Kogan CS, et al. Age-dependent cognitive changes in carriers of the fragile X syndrome. Cortex 2008;44:628-636.

55. Loesch DZ, Cook M, Litewka L, et al. A low symptomatic form of neurodegeneration in younger carriers of the FMR1 premutation, manifesting typical radiological changes. J Med Genet 2008;45:179-181.

56. Jacquemont S, Hagerman RJ, Leehey MA, et al. Penetrance of the fragile $\mathrm{X}$-associated tremor/ataxia syndrome in a premutation carrier population. JAMA 2004;291:460-469

57. Berry-Kravis E, Abrams L, Coffey SM, et al. Fragile X-associated tremor/ataxia syndrome: clinical features, genetics, and testing guidelines. Mov Disord 2007;22:2018-2030

58. Jacquemont S, Orrico A, Galli L, et al. Spastic paraparesis, cerebellar ataxia, and intention tremor: a severe variant of FXTAS? J Med Genet 2005;42:14.

59. Jacquemont S, Leehey MA, Hagerman RJ, Beckett LA, Hagerman PJ. Size bias of fragile $X$ premutation alleles in late-onset movement disorders. J Med Genet 2006:43:804-809.

60. Baba Y, Uitti RJ. Fragile X-associated tremor/ataxia syndrome and movements disorders. Curr Opin Neurol 2005;18:393-398.

61. Hall DA, Hagerman RJ, Hagerman PJ, Jacquemont S, Leehey MA. Prevalence of FMR1 repeat expansions in movement disorders. A systematic review. Neuroepidemiology 2006;26:151-155.

62. Berry-Kravis E, Lewin F, Wuu J, et al. Tremor and ataxia in fragile X premutation carriers: blinded videotape study. Ann Neurol 2003;53:616-623.

63. Loesch DZ, Churchyard A, Brotchie P, Marot M, Tassone F. Evidence for, and a spectrum of, neurological involvement in carriers of the fragile $X$ pre-mutation: FXTAS and beyond. Clin Genet 2005;67:412-417.

64. Grigsby J, Brega AG, Leehey MA, et al. Impairment of executive cognitive functioning in males with fragile $X$-associated tremor/ataxia syndrome. Mov Disord 2007;22:645-650.

65. Tassone F, Adams J, Berry-Kravis EM, et al. CGG repeat length correlates with age of onset of motor signs of the fragile X-associated tremor/ataxia syndrome (FXTAS). Am J Med Genet B Neuropsychiatr Genet 2007;144:566-569.

66. Leehey MA, Berry-Kravis E, Goetz CG, et al. FMR1 CGG repeat length predicts motor dysfunction in premutation carriers. Neurology 2008;70: 1397-1402.

67. Dombrowski C, Levesque S, Morel ML, Rouillard P, Morgan K, Rousseau F. Premutation and intermediate-size FMR1 alleles in 10572 males from the general population: loss of an AGG interruption is a late event in the generation of fragile X syndrome alleles. Hum Mol Genet 2002;11:371-378.

68. Hall DA, Berry-Kravis E, Hagerman RJ, Hagerman PJ, Rice CD, Leehey MA Symptomatic treatment in the fragile $\mathrm{X}$-associated tremor/ataxia syndrome. Mov Disord 2006;21:1741-1744.

69. McConkie-Rosell A, Finucane B, Cronister A, Abrams L, Bennett RL, Pettersen BJ. Genetic counseling for fragile x syndrome: updated recommendations of the national society of genetic counselors. J Genet Couns 2005; 14:249-270.

70. Reis $A H$, Ferreira AC, Gomes KB, et al. Frequency of FMR1 premutation in individuals with ataxia and/or tremor and/or Parkinsonism. Genet Mol Res 2008:7:74-84.

71. Nitrini R, Gonçalves MRR, Capelli LP et al. Dementia in fragile X-associated tremor/ataxia syndrome. Dement Neuropsychol 2010;4:79-83.

72. McConkie-Rosell A, Abrams L, Finucane B, et al. Recommendations from multi-disciplinary focus groups on cascade testing and genetic counseling for fragile X-associated disorders. J Genet Couns 2007; 16:593-606.

73. Elaine B, Spector EB, Kronquist K. Technical standards and guidelines for fragile $X$ testing: a revision to the disease-specific supplements to the standards and guidelines for clinical genetics laboratories of the American College of Medical Genetics. Available at www.acmg.net/Pages/ACMG_Activities/ stds-2002/fx.htm Accessed (04/01/2010). 